\title{
Pulmonary function testing and sarcoidosis: A review
}

\author{
Rissmiller Richard W and W. Ennis James* \\ Division of Pulmonary, Critical Care and Sleep Medicine, Medical University of South Carolina, Charleston, SC, USA
}

\begin{abstract}
Sarcoidosis is a granulomatous disease of unknown etiology that can affect any organ. Identification of sarcoidosis patients is key to improving their outcomes and reducing health care costs. Unfortunately, diagnosis can be complex and require significant testing. Pulmonary function testing (PFT), along with chest imaging, is often the initial testing obtained by the respiratory physician in evaluation of the patient with dyspnea and is often used to monitor response to therapy. PFTs are one of many potentially useful tools when following patients with pulmonary sarcoidosis. The goal of this review is to discuss the patterns and pitfalls of PFT interpretation in patients with sarcoidosis.
\end{abstract}

\section{Introduction}

Sarcoidosis is a granulomatous inflammatory disease of unknown etiology that can affect any organ, but most commonly affects the lungs [1]. The diagnosis of pulmonary sarcoidosis can be difficult. Patients are often left undertreated or misdiagnosed due to the diverse presentation of sarcoidosis, which can be further confounded by the numerous possible findings noted on Pulmonary Function Testing. Unfortunately, pulmonary function tests (PFTs) are not a reliable means for detecting the presence of pulmonary sarcoidosis, nor do they provide an accurate estimate of the extent of parenchymal disease [2]. PFTs are only a piece of a puzzle when diagnosing pulmonary sarcoidosis (including a consistent clinical presentation, imaging, and biopsy). However, PFTs are often performed as part of the initial evaluation of a sarcoidosis patient and can be helpful in phenotyping pulmonary sarcoidosis as well as evaluating for alternative diagnoses.

Typical pulmonary symptoms include nonproductive cough and exertional dyspnea, and patients often report wheezing. Treatment of pulmonary sarcoidosis should be considered when patients have symptoms impairing quality of life or when the granulomatous inflammation causes progressive loss of pulmonary function, affects the heart, brain, kidneys, or causes hypercalcemia. PFTs can also provide evidence of worsening parenchymal disease in patients with symptoms that are unresponsive to treatment.

The ability to identify patients suffering from sarcoidosis provides an opportunity to improve both patient outcomes and decrease healthcare costs [1]. The prevalence of sarcoidosis is increasing in the United States, with at least 185,000 patients seeking out medical care annually, so while it is considered an orphan disease, the prevalence of disease may be higher than currently appreciated [1]. There is significant regional variation in the prevalence of disease, so familiarity with the disease in certain locations is essential. Highest rates occur in the Northeast, South and Midwest [3]. In the U.S., the incidence of sarcoidosis is highest in females and African Americans but can be seen in all racial and ethnic groups [3]. There tends to be two peaks of incidence, one at about age 30 and another at about age 65, therefore, a large age range can be affected [4]. Fifty five percent of patient diagnosed with sarcoidosis are over 55 years of age at the time of diagnosis [3].

\section{Pathophysiology of pulmonary sarcoidosis}

The cause of sarcoidosis is not well delineated. It is postulated that there is an environmental trigger of the disease, which results in granulomatous inflammation with a predominance of T-cell helper lymphocytes [5]. There is increasing evidence that genetics play an important role in the pathogenesis, and certain HLA subtypes are associated with disease risk as well as clinical phenotype. In pulmonary sarcoidosis, T-cell lymphocytic alveolitis precedes the histologic finding of non-necrotizing or non-caseating granulomas (although $5-10 \%$ may show areas of focal necrosis) [6]. Sarcoidosis is a diagnosis of exclusion and requires both a consistent clinical presentation and histologic confirmation of granulomatous inflammation.

\section{Overview of pulmonary function tests}

Pulmonary function testing is an essential tool for the pulmonologist. Insight into underlying pulmonary pathophysiology can be obtained from comparison to normal values (based on age, height, race and sex) and previous values from the same patient. The percentage of predicted normal is used to grade the severity of the abnormality.

PFTs provide objective assessment of lung function. This allows more accurate definition of respiratory mechanics, lung parenchymal function, gas exchange and cardiopulmonary interaction. These results are reproducible and quantitative, allowing monitoring over time. Respiratory symptoms alone tend to correlate poorly with disease severity and progression, so objective measurement is important [7]. PFTs are used to screen for the presence of obstructive and restrictive diseases, evaluate patients prior to surgery, document the progression of pulmonary disease, document the effectiveness of therapeutic intervention and monitor pulmonary drug toxicity [8]. Contraindications to PFTs include recent eye surgery, thoracic, abdominal and cerebral aneurysms, active hemoptysis, pneumothorax and unstable angina/MI within the past month [9].

${ }^{\star}$ Correspondence to: W. Ennis James, Susan Pearlstine Sarcoidosis Center of Excellence, Division of Pulmonary, Critical Care and Sleep Medicine, Medical University of South Carolina, Charleston, SC, USA; E-mail: jamesw@musc.edu

Received: March 22, 2018; Accepted: April 17,2018; Published: April 20, 2018 
Spirometry measures the volume of air exhaled or inhaled by a patient as a function of time [7]. Forced expiratory vital capacity (FVC) maneuver requires the patient to forcefully expel air from a point of maximal inspiration (total lung capacity [TLC]) to a point of maximal expiration (residual volume $[\mathrm{RV}]$ ). The forced expiratory volume in the first second of the FVC maneuver (FEV1) and the FEV1/FVC ratio are keys to determine whether obstruction is present. The graphic display of inspiration and expiration plotted as a function of volume (flowvolume loop) allows identification of subtle abnormalities of airflow. The FEV1/FVC (usually reported as a percentage) indicates what percentage of the total FVC was expelled from the lungs during the first second of forced exhalation. While there is some controversy in the literature as to what defines obstruction, a ratio of less than $70 \%$ usually is abnormal and indicates airflow obstruction [8].

Total lung capacity is more difficult to measure. Although spirometry can measure inhaled and exhaled volumes, it cannot determine the total amount of air in the lungs at full inspiration (TLC), the amount of air remaining in the lungs at the end of quiet (tidal) expiration (functional residual capacity), or the amount of air remaining after maximal expiration (RV). These volumes can be determined by any inert gas dilution and body plethysmography, which uses Boyle's law to determine lung volumes from pressure and volume changes during respiration in a sealed box [7].

Functional residual capacity (FRC) is the volume of air in the lungs at end-expiratory tidal position. The FRC functions to help maintain a steady arterial oxygen tension, help prevent atelectasis and helps minimize work of breathing. The FRC can then be added to the vital capacity to determine the total lung capacity. A total lung capacity of less than $80 \%$ of predicted is generally considered to be consistent with restrictive lung disease [8].

Another PFT maneuver is the diffusion capacity (DLCO), which attempts to define diffusion characteristics of the membrane through which oxygen and carbon dioxide diffuse [8]. Diffusing capacity depends upon the rate at which gas enters the blood divided by its driving pressure and estimates the ability of the lungs to transport inhaled gas from alveoli to pulmonary capillaries. This transport depends on the thickness of alveolar-capillary membrane, the hemoglobin concentration and the pulmonary blood flow [7]. Diffusion capacity is generally estimated using the single breath test using carbon monoxide (CO) [8]. CO is used due to its high affinity for hemoglobin, which is approximately 200 times that of oxygen. At normal conditions there is a low blood concentration and pulmonary concentration. DLCO reductions occur in structural lung disease, pulmonary hypertension, congestive heart failure, reductions in effective alveolar units (eg, lung resection, emphysema), and anemia [7]. A high DLCO is most frequently associated with large lung volumes, obesity and asthma, although it can also be seen in alveolar hemorrhage or when the patient valasalvas during testing [10].

The 6-min walk test has been used to assess the functional status of patients with a wide variety of pulmonary diseases, including pulmonary hypertension, COPD, and idiopathic pulmonary fibrosis.

This testing is able to predict mortality for several end-stage lung diseases and has largely replaced cardiopulmonary exercise testing in the assessment of lung disease. It is much easier to perform, with lower associated low cost and good reproducibility [11].

\section{Pulmonary function in sarcoidosis}

The majority of sarcoidosis patients will have normal PFTs [12] but may also show a restrictive or obstructive pattern ${ }^{2}$. The most frequent
PFT abnormality noted in sarcoidosis patients is a reduced diffusing capacity, which can be due to parenchymal involvement or due to the presence of pulmonary hypertension, which should be considered in sarcoidosis patients who have clinical findings consistent with right heart failure $[12,13]$. The presence of statistically significant differences in all PFT parameters among the patient groups with different radiographic stages of sarcoidosis has been shown [12].

However, pulmonary function testing may show normal results even when anatomic changes documented by imaging studies are severe [14]. In one study [13], only $14.6 \%$ of consecutive newly diagnosed sarcoid patients had restriction or mixed restriction and obstruction at presentation. Obstruction was noted in $9.7 \%$ of patients, with $47.9 \%$ having increased RV/TLC ratio consistent with air trapping and some element of obstruction. This mild obstruction was prevalent from early stages of the disease with the tendency to coexist with restriction as the disease advanced. The DLCO was reduced in $69.4 \%$ of patients, which tends to be a common finding in our practice as well.

Pulmonary function testing allows the clinician to assess changes in the disease course of the individual patient through sequential measurements [2]. Although, changes in FVC over time only partially correlate with HRCT findings, a combined analysis with DLCO is likely more accurate for assessing disease evolution [15]. A common radiographic presentation of a patient with sarcoidosis is shown in Figure 1.

\section{Obstructive lung disease}

Bronchial distortion caused by pulmonary parenchymal fibrosis results in lower expiratory flow rates. Interstitial disease can cause airway distortion caused by parenchymal changes or luminal stenosis, but sarcoidosis can also involve the large and small airways, causing obstructive airways disease. Sarcoidosis can affect the entire length of the respiratory tract, including the upper airway and the terminal

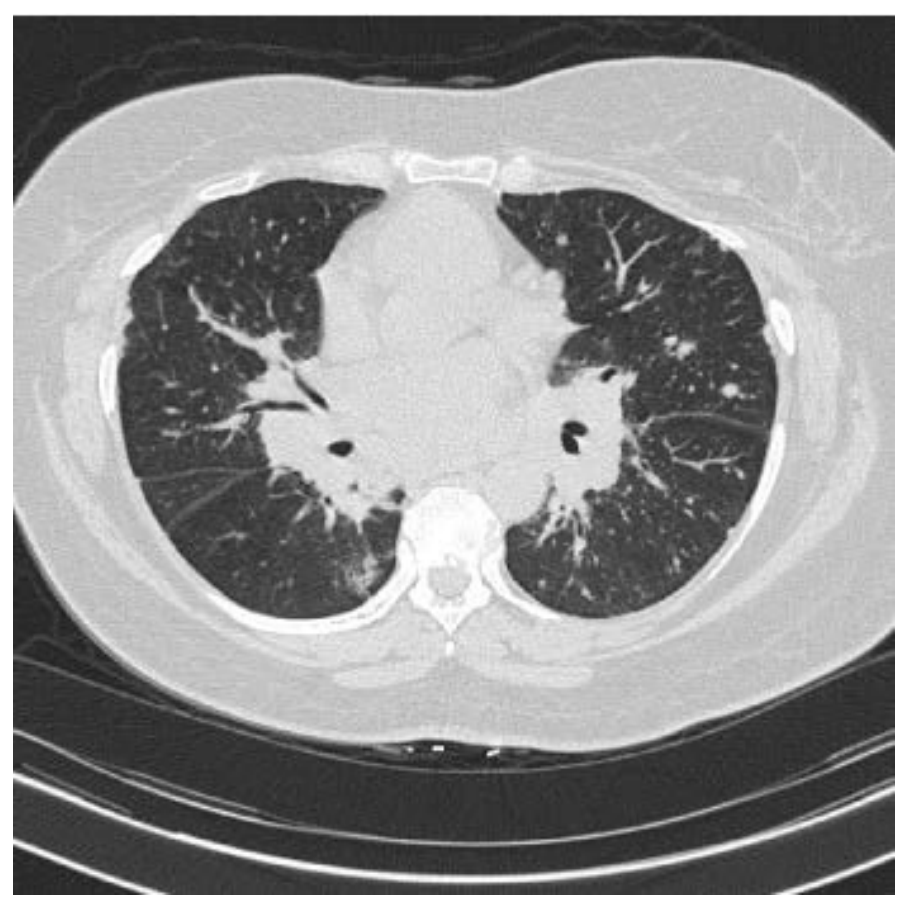

Figure 1. High resolution CT scan

Innumerable pulmonary nodules (subpleural, perifissural and peribronchovascular) with bulky mediastinal and hilar lymphadenopathy. 
bronchioles [16]. Mucosal erythema and edema and cobblestone mucosa (bunching of small yellow lesions, more common in lobar and segmental bronchi) can be seen. Bronchial stenosis can be seen in the lobar and segmental bronchi, but mucosal biopsy may or may not show granulomas $[13,17]$. Airway distortion leading to obstruction is more likely in advanced parenchymal disease. Airway hyperreactivity occurs in up to $20 \%$ of sarcoid patients [14]. Endobronchial involvement increases the risk of airflow limitation which can occur in up to $60 \%$ of sarcoid patients and can be seen in any stage [14]. Supraglottic structures can also be involved. Oral, nasal, and pharyngeal mucosal changes can lead to hoarseness, dysphagia, laryngeal paralysis, airway obstruction and obstructive sleep apnea. It has been reported that 2.3 to $6 \%$ of sarcoid patients exhibit involvement of the upper respiratory tract $[18,19]$. The trachea and main bronchi are less frequently affected than the lobar, segmental, subsegmental, and distal airways. Sarcoid granulomas of trachea, main carina, and major bronchi by themselves seldom produce significant obstructive symptoms or airway dysfunction, this is usually seen in involvement in the smaller airways [18]. Obstructive airway disease has been noted to be more common in African-American patients with sarcoidosis, compared with much lower rates in white European and American and in Japanese patients [20].

Large airway stenosis has been described in patients with sarcoidosis, and while fixed upper airway obstruction is unusual, it has been reported [21]. Extrinsic compression of the central airways by the enlarged mediastinal and hilar lymph nodes is uncommon.

Bronchoscopy can be useful in the diagnosis and management of airway sarcoidosis. Bronchoscopic abnormalities have been observed in up to $60 \%$ of patients with sarcoidosis [17]. However, in that study endobronchial disease was not associated with airflow obstruction. Endobronchial occlusion by sarcoid granulomas in the submucosa or an endobronchial polyp caused by sarcoid granulomas can be seen [22]. An example of an obstructive pattern of PFTs in sarcoidosis is shown in Figure 2.

\section{Restrictive lung disease}

Restrictive impairment is mainly caused by extensive fibrosis secondary to sarcoid granulomas or by interstitial pneumonia which coexistent with pulmonary sarcoidosis. Sarcoidosis is generally classified as a restrictive lung disease. This is due to the fact that it primarily affects the structure of the lung. It is generally characterized by reduced compliance of the lung. Total lung capacity can be particularly helpful when a patient has severe airflow obstruction and has a reduction in FVC due to air trapping. In this case, a normal or increased total lung capacity excludes an associated restrictive process, and the reduction in FVC is actually a pseudorestriction as seen with a significant obstruction.

It has been shown in the past that lung compliance correlated with vital capacity in patients with sarcoidosis [23], however, it has been also been shown that the vital capacity and the TLC do not correlate in patients with sarcoidosis. In symptomatic patients, the entire PFT pattern (FVC, TLC and DLCO) should be considered in the interpretation of a restrictive ventilatory defect to avoid an inaccurate diagnosis. Intrathoracic lymphadenopathy occurs in approximately $75 \%$ to $90 \%$ of patients, and symmetric bilateral hilar and/or paratracheal adenopathy can contribute to restriction.

\section{Impairment in diffusion capacity}

DLCO is the most sensitive parameter to detect a loss of functional alveolar surface area and measures the forces at work in molecular movement with its concentration gradient from the alveolar surface through to the hemoglobin molecule [24]. Hemoglobin concentration is a very important measurement in interpreting reductions in DLCO. Because the hemoglobin present in the alveolar capillaries serves as a carbon monoxide sink, a DLCO may be decreased when the patient is anemic, and hematologic abnormalities are quite common in patients with sarcoidosis, with anemia due to noncaseating granulomas and absent iron stores in the bone marrow [25]. Reduction in DLCO is highly predictive of gas exchange abnormalities at exercise in patients with sarcoidosis, and DLCO and arterial desaturation at exercise have been reported to be the strongest functional parameters that correlate with the extent and the severity of sarcoidosis, assessed by either pathologic scores or high-resolution CT. Also, this reduction correlates with a loss of alveolar membrane diffusing capacity, not alterations in pulmonary capillary blood volume [26].

Pulmonary hypertension $(\mathrm{PH})$ is seen in sarcoidosis $(5-15 \%$ of patients) but is present in over $50 \%$ of patients with persistent dyspnea, and there is a strong inverse correlation between mean pulmonary artery pressure and DLCO [27,28]. PH complicating sarcoidosis is associated with reduced exercise capacity. $\mathrm{PH}$ is more often associated with advanced sarcoidosis and reduced lung volumes, but severe $\mathrm{PH}$ in the absence of significant restriction is seen. Reduced DLCO and either resting hypoxemia or exercise desaturation correlate with the presence of $\mathrm{PH}$ in sarcoidosis [27].

The prognostic value of PFTs in sarcoidosis is supported by a recent study by Walsh and colleagues, who found that a composite physiologic index (CPI) score greater than 40 was an independent predictor of mortality. The CPI score is derived using percent predicted values for FVC, FEV1 and DLCO [29].

An example of a restrictive defect with a markedly reduced DLCO in a sarcoidosis patient is shown in Figure 3.

\section{Exercise testing}

Both six-minute walk distance (6MWD) and desaturation during $6 \mathrm{MWT}$ are valuable tools for predicting functional capacity and mortality in various pulmonary and non-pulmonary diseases. Normal spirometry and/or DLCO measurements do not exclude impaired gas exchange and exercise limitations during exercise [30]. Six-minute walk distance is reduced in the majority of sarcoidosis patients ${ }^{11}$. Several factors are associated with a reduced 6MWD, including FVC, oxygen saturation with exercise, and self-reported respiratory health ${ }^{11}$. Patients with more severe sarcoidosis tend to have a greater decline in oxygen desaturation during the 6MWT. Oxygen desaturation during 6MWT is a second measured outcome of this test which should considered in assessing sarcoidosis severity [11]. There is no correlation between 6MWD and spirometry [31]. Therefore, 6MWD may provide a more complete evaluation of respiratory mechanics (as compared to PFTs alone). However, impaired physical capacity in sarcoidosis patients may be related to factors other than their intrinsic lung disease, including corticosteroid use, underlying pulmonary vascular disease, fatigue, depression, among other causes [11,31].

It has also been suggested that cardiopulmonary exercise testing (CPET) with blood gas analysis may be helpful, especially when there is a discrepancy between clinical findings and physiologic tests at rest [32]. CPET may offer added value in detecting impaired gas exchange beyond DLCO in sarcoidosis patients with otherwise unexplained symptoms. 


$\begin{array}{ll}\text { Spirometry } & \\ \text { FVC } & \text { Liters } \\ \text { FEV1 } & \text { Liters } \\ \text { FEV1/FVC } & \% \\ \text { FEF25-75\% } & \text { L/sec } \\ \text { PEF } & \text { L/sec } \\ \text { FET100\% } & \text { Sec } \\ & \\ \text { Lung Volumes } & \\ \text { TLC } & \text { Liters } \\ \text { VC } & \text { Liters } \\ \text { FRC PL } & \text { Liters } \\ \text { ERV } & \text { Liters } \\ \text { RV } & \text { Liters } \\ \text { RV/TLC } & \% \\ & \\ \text { Diffusing Capacity } & \\ \text { DLCO } & \mathrm{mL} / \mathrm{mmH} / \mathrm{min} \\ \text { DL Adj } & \mathrm{mL} / \mathrm{mmHg} / \mathrm{min} \\ \text { DLCO } / \mathrm{mA} & \mathrm{mL} / \mathrm{mHg} / \mathrm{min} / \mathrm{L} \\ \text { DLNA Adj } & \mathrm{mL} / \mathrm{mHg} / \mathrm{min} / \mathrm{L} \\ \text { VA } & \text { Liters } \\ \text { IVC } & \text { Liters }\end{array}$

$\begin{array}{rrrrrr}\text { Ref } & \text { Pre } & \text { \% Ref } & \text { Post } & \text { \% Ref } & \text { \%Chg } \\ 3.23 & 2.91 & 90 & 3.12 & 96 & 7 \\ 2.47 & 1.31 & 53 & 1.42 & 57 & 8 \\ 77 & 45 & & 45 & & \\ 2.16 & 0.37 & 17 & 0.39 & 18 & 4 \\ 6.08 & 4.71 & 77 & 4.71 & 78 & 0 \\ & 15.05 & & 15.14 & & 1\end{array}$

$\begin{array}{rrr}4.97 & 5.84 & 117 \\ 3.23 & 3.04 & 94 \\ 3.04 & 3.61 & 119 \\ 1.01 & 0.79 & 78 \\ 1.94 & 2.79 & 144 \\ 39 & 48 & \end{array}$

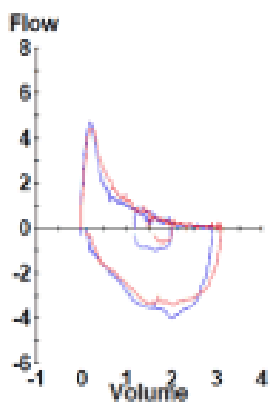

$\begin{array}{rrr}17.6 & 9.2 & 52 \\ 17.6 & 9.2 & 52 \\ 3.74 & 1.91 & 51 \\ & 1.91 & \\ 4.97 & 4.84 & 97 \\ & 2.91 & \end{array}$

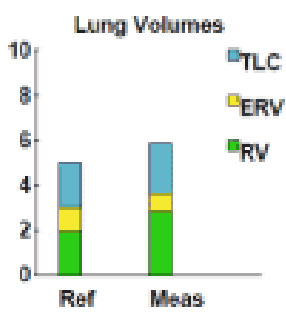

Figure 2. Obstructive lung disease in sarcoidosis

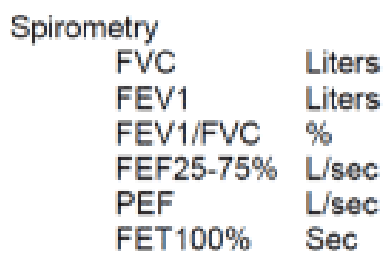

$\begin{array}{rrrrrr}\text { Ref } & \text { Pre } & \text { \% Ref } & \text { Post } & \text { \% Ref } & \text { \%Chg } \\ & & & & & \\ 3.44 & 2.67 & 78 & 2.71 & 79 & 2 \\ 2.89 & 1.88 & 65 & 1.96 & 68 & 4 \\ 85 & 71 & & 72 & & \\ 3.29 & 1.23 & 37 & 1.36 & 41 & 11 \\ 7.17 & 5.52 & 77 & 4.49 & 63 & -19 \\ & 7.16 & & 7.56 & & 6\end{array}$

$\begin{array}{ll}\text { Lung Volumes } & \\ \text { TLC } & \text { Liters } \\ \text { VC } & \text { Liters } \\ \text { FRC PL } & \text { Liters } \\ \text { ERV } & \text { Liters } \\ \text { RV } & \text { Liters } \\ \text { RV } / T L C & \%\end{array}$

$\begin{array}{rrr}5.54 & 4.40 & 79 \\ 3.44 & 2.67 & 78 \\ 3.21 & 2.38 & 74 \\ 1.31 & 0.64 & 48 \\ 1.76 & 1.73 & 98 \\ 30 & 39 & \end{array}$

$\begin{array}{ll}\text { Diffusing Capacity } & (\mathrm{Hb} 9.2) \\ \text { DLCO } & \mathrm{mL} / \mathrm{mmHg} / \mathrm{min} \\ \text { DL Adj } & \mathrm{mL} / \mathrm{mmHg} / \mathrm{min} \\ \text { DLCO } / \mathrm{MA} & \mathrm{mL} / \mathrm{mHg} / \mathrm{min} / \mathrm{L} \\ \text { DL } / \mathrm{NA} \text { Adj } & \mathrm{mL} / \mathrm{mHg} / \mathrm{min} / \mathrm{L} \\ \text { VA } & \text { Liters } \\ \text { IVC } & \text { Liters }\end{array}$

$\begin{array}{lll}22.3 & 10.4 & 47 \\ 22.3 & 12.4 & 56 \\ 4.59 & 3.08 & 67 \\ & 3.66 & \\ 5.54 & 3.39 & 61 \\ & 2.42 & \end{array}$

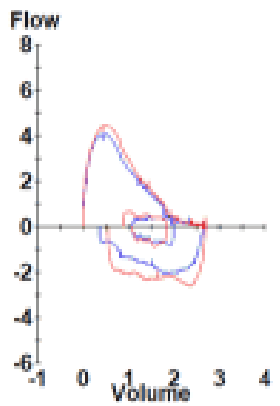

Figure 3. Mild restriction with markedly reduced DLCO

\section{Outcomes and treatment}

Disease resolution is seen in the majority of patients with sarcoidosis. Spontaneous remission was observed in $62.2 \%$ in one study, and remission or improvement following treatment was seen in another $18.7 \%$ [33]. Chronic or progressive sarcoidosis is seen in $10-30 \%$ of patients [34]. Currently, there are only two FDA approved drugs for the treatment of pulmonary sarcoidosis: Prednisone and repository corticotropin injection. Treatment with Prednisone is considered first line therapy for most forms of sarcoidosis. Repository corticotropin injection has received relatively little attention to date and lacks robust research to support its use as anything other than a third or fourth line medication [35].

Several studies have demonstrated the value of methotrexate in patients with refractory disease, and it generally considered the initial choice second-line (or steroid sparing) medication [36]. Improvements in vital capacity or other affected symptomatic organ was noted in 33 of 50 patients treated with methotrexate and corticosteroids were discontinued in an additional six patients who remained stable with clinical or symptomatic improvement. Azathioprine and Leflunomide have also been successfully used as alternative second line agents [37, 38]. 
The tumor necrosis factor alpha (TNF- $\alpha$ ) antagonist infliximab appears to be an effective third line medication in sarcoidosis and can be used if patients have intolerance or therapeutic failure of methotrexate. A retrospective study indicates that long-term infliximab is very efficient and safe in patients with chronic steroid-resistant sarcoidosis, and patients with predominantly extra-pulmonary sarcoidosis seem to get significant benefit as well [39].

\section{Conclusion}

Advanced pulmonary sarcoidosis patients are often on one or more immunomodulating therapies and requires close care coordination and follow-up with PFTs, symptom evaluation and imaging. As an orphan disease, there is variability in sarcoidosis practice patterns between centers. While no follow-up guidelines exist for sarcoidosis, many experts recommend PFTs yearly (along with lab evaluation, ECG, and ophthalmology evaluation). Primary care physicians and community pulmonologists will remain on the front lines of diagnosis for the majority of sarcoidosis patients and are the most important providers for helping to establish the diagnosis of the disease and initiating effective disease management.

\section{Acknowledgment}

Work was supported in part by the Susan Pearlstine Sarcoidosis Center of Excellence at the Medical University of South Carolina, Charleston SC.

\section{References}

1. Baughman RP, Costabel U, du Bois RM (2008) Treatment of sarcoidosis. Clin Chest Med 29: 533-548, ix-x. [Crossref]

2. Winterbauer RH, Hutchinson JF (1980) Use of pulmonary function tests in the management of sarcoidosis. Chest 78: 640-647. [Crossref]

3. Erdal BS, Clymer BD, Yildiz VO, Julian MW, Crouser ED (2012) Unexpectedly high prevalence of sarcoidosis in a representative U.S. Metropolitan population. Respir Med 106: 893-899. [Crossref]

4. Iannuzzi MC, Rybicki BA, Teirstein AS (2007) Sarcoidosis. N Engl J Med 357: 2153 2165. [Crossref]

5. Baughman RP, Field S, Costabel U, Crystal RG, Culver DA, et al. (2016) Sarcoidosis in America. Analysis Based on Health Care Use. Ann Am Thorac Soc 13: 1244-1252. [Crossref]

6. Mañá J, Gómez-Vaquero C, Montero A, Salazar A, Marcoval J, et al. (1999) Löfgren's syndrome revisited: a study of 186 patients. Am J Med 107: 240-245. [Crossref]

7. Ranu H, Wilde M, Madden B (2011) Pulmonary function tests. Ulster Med J 80: 84-90. [Crossref]

8. Littner MR (1993) Getting the most from your pulmonary function lab. $J$ Respir Dis 14: 1043-1061.

9. Cooper BG (2011) An update on contraindications for lung function testing. Thorax 66: 714-723. [Crossref]

10. Saydain G, Beck KC, Decker PA, Cowl CT, Scanlon PD (2004) Clinical significance of elevated diffusing capacity. Chest 125: 446-452. [Crossref]

11. Baughman RP, Sparkman BK, Lower EE (2007) Six-minute walk test and health status assessment in sarcoidosis. Chest 132: 207-213. [Crossref]

12. Danila E, Jurgauskiené V, Malickaité R (2008) BAL fluid cells and pulmonary function in different radiographic stages of newly diagnosed sarcoidosis. Adv Med Sci 53: 228233. [Crossref]

13. Calaras D, Munteanu O, Scaletchi V, Simionica I, Botnaru V (2017) Ventilatory disturbances in patients with intrathoracic sarcoidosis - a study from a functional and histological perspective. Sarcoidosis Vasculitis and Diffuse Lung Diseases 34: 58-67.

14. Polychronopoulos VS, Prakash UBS (2009) Airway involvement in sarcoidosis. Chest 136: 1371-1380. [Crossref]

15. Gafà G1, Sverzellati N, Bonati E, Chetta A, Franco F, et al. Follow-up in pulmonary sarcoidosis: comparison between HRCT and pulmonary function tests. Radiol Med. 2012;117:968. [Crossref]
16. Morgenthau AS, Teirstein AS (2011) Sarcoidosis of the upper and lower airways. Expert Rev Respir Med 5: 823-833. [Crossref]

17. Shorr AF, Torrington KG, Hnatiuk OW (2001) Endobronchial biopsy for sarcoidosis: a prospective study. Chest 120: 109-114. [Crossref]

18. Baughman RP, Teirstein AS, Judson MA, Rossman MD, Yeager H Jr, et al. (2001) Clinical characteristics of patients in a case control study of sarcoidosis. Am J Respir Crit Care Med 164: 1885-1889. [Crossref]

19. James DG, Barter S, Jash D, MacKinnon DM, Carstairs LS (1982) Sarcoidosis of the upper respiratory tract (SURT). J Laryngol Otol 96: 711-718. [Crossref]

20. Sharma OP, Johnson R (1988) Airway obstruction in sarcoidosis. A study of 123 nonsmoking black American patients with sarcoidosis. Chest 94: 343-346. [Crossref]

21. Miller A, Brown LK, Teirstein AS (1985) Stenosis of main bronchi mimicking fixed upper airway obstruction in sarcoidosis. Chest $88: 244-248$. [Crossref]

22. Corsello BF, Lohaus GH, Funahashi A (1983) Endobronchial mass lesion due to sarcoidosis: complete resolution with corticosteroids. Thorax 38: 157-158. [Crossref]

23. Marshall R, Karlish AJ (1971) Lung function in sarcoidosis. An investigation of the disease as seen at a clinic in England and a comparison of the value of various lung function tests. Thorax 26: 402-405. [Crossref]

24. Crapo RO, Forster RE 2nd (1989) Carbon monoxide diffusing capacity. Clin Chest Med 10: 187-198. [Crossref]

25. Lower EE, Smith JT, Martelo OJ, Baughman RP (1988) The anemia of sarcoidosis Sarcoidosis 5: 51-55. [Crossref]

26. Lamberto C, Nunes H, LeToumelin P, Duperron F, Valeyre D, et al. (2004) Membrane and Capillary Blood Components of Diffusion Capacity of the Lung for Carbon Monoxide in Pulmonary Sarcoidosis: Relation to Exercise Gas Exchange. Chest 125 2061-2068. [Crossref]

27. Girgis R (2009) Pulmonary Hypertension Associated with Sarcoidosis. Advances in PH Journal.

28. Baughman RP, Engel PJ, Taylor L, Lower EE (2010) Survival in sarcoidosis-associated pulmonary hypertension: the importance of hemodynamic evaluation. Chest 138:10781085 [Crossref]

29. Walsh SL, Wells AU, Sverzellati N, Keir GJ, Calandriello L, et al. (2014) An integrated clinicoradiological staging system for pulmonary sarcoidosis: a case-cohort study. Lancet Respir Med 2:123-130. [Crossref]

30. Karetzky M, McDonough M (1996) Exercise and resting pulmonary function in sarcoidosis. Sarcoidosis Vasc Diffuse Lung Dis 13: 43-49. [Crossref]

31. Samadi K, Abedini A, Kharabian S, Rezaian L (2016) Six-Minute Walking Test (6MWT) Results Assessment in Pulmonary Sarcoidosis Patients. J Pulm Respir Med 6: 341.

32. Marcellis RG, Lenssen AF, de Vries GJ, Baughman RP, van der Grinten CP, et al. (2013) Is there an added value of cardiopulmonary exercise testing in sarcoidosis patients? Lung 191: 43-52. [Crossref]

33. Statement on sarcoidosis. Joint Statement of the American Thoracic Society (ATS) the European Respiratory Society (ERS) and the World Association of Sarcoidosis and Other Granulomatous Disorders (WASOG) adopted by the ATS Board of Directors and by the ERS Executive Committee, February 1999 (1999) Am J Respir Crit Care Med 160: 736-755. [Crossref]

34. Inoue $\mathrm{Y}$, Inui N1, Hashimoto D, Enomoto N, Fujisawa T, et al. (2015) Cumulative Incidence and Predictors of Progression in Corticosteroid-Naïve Patients with Sarcoidosis. PLoS One 10: e0143371. [Crossref]

35. Judson MA, Baughman RP, Thompson BW, Teirstein AS, Terrin ML, et al. (2003) Two year prognosis of sarcoidosis: the ACCESS experience. Sarcoidosis Vasc Diffuse Lung Dis 20: 204-211. [Crossref]

36. Lower EE, Baughman RP (1995) Prolonged use of methotrexate for sarcoidosis. Arch Intern Med 155: 846-851. [Crossref]

37. Vorselaars ADM, Wuyts WA, Vorselaars VMM, Zanen P, Deneer VHM, et al. (2013) Methotrexate vs azathioprine in second-line therapy of sarcoidosis. Chest 144: 805812. [Crossref]

38. Baughman RP, Lower EE (2004) Leflunomide for chronic sarcoidosis. Sarcoidosis Vasc Diffuse Lung Dis 21: 43-48. [Crossref]

39. Hostettler KE, Studler U, Tamm M, Brutsche MH (2012) Long-term treatment with infliximab in patients with sarcoidosis. Respiration 83: 218-224. [Crossref]

Copyright: (C2018 Richard RW. This is an open-access article distributed under the terms of the Creative Commons Attribution License, which permits unrestricted use, distribution, and reproduction in any medium, provided the original author and source are credited. 